\title{
Moral Sensitive Human Resource Development: A Conceptual Model and Its Implementation
}

\author{
Saleh Afroogh ${ }^{1}$, Seyyed Abbas Kazemi ${ }^{2}$, Faegheh Hajhosseini ${ }^{3} \&$ Amin Alizadeh $^{4}$ \\ ${ }^{1}$ Department of Philosophy, The State University of New York at Albany, Albany, USA \\ 2 Department of Philosophy, Institute for Research in Fundamental Sciences, Tehran, Iran \\ ${ }^{3}$ Department of Comparative Literature, The University at Buffalo, Buffalo, USA \\ ${ }^{4}$ Department of Educational Administration \& Human Resource Development, Texas A\&M University, College \\ Station, USA
}

Correspondence: Saleh Afroogh, Department of Philosophy, The State University of New York at Albany, Albany, USA. E-mail: safroogh@albany.edu

\author{
Received: March 10, $2021 \quad$ Accepted: April 20, $2021 \quad$ Online Published: April 30, 2021 \\ doi:10.5539/ijbm.v16n6p1 URL: https://doi.org/10.5539/ijbm.v16n6p1
}

\begin{abstract}
In this paper, we propose a conceptual model to improve moral sensitivity in human resource development (HRD) to assist human resource (HR) practitioners in contending with moral challenges in HRD. The literature on the relationship between ethics and HRD suggests that the organizational and employee development discipline deals with ethical issues at three different levels: Individual, organizational and communal, and international levels. In section I, we elaborate on moral challenges facing HRD. In section II, we conceptualize moral sensitive HRD, proposing a conceptual model in virtue of some essential ethical theories and concepts that assist HRD in grappling with those problems. We will show how each theory and concept can help HRD to deal with relevant problems. In section III, we elaborate on practical approaches to implement moral sensitivity in HRD. We put forward some strategies that help HRD bring those theories and concepts to bear on the ethical problems facing this discipline. Finally, we discuss moral education through learning theories to cultivate moral concepts and ethical dimensions in HRD education.
\end{abstract}

Keywords: moral sensitive HRD, moral theory, ethics, HRD, social justice

\section{Introduction}

Expectations on business leaders and organizations have changed dramatically in the last few years. Servant leadership with the focus on humility, and employee empowerment has become one of the most needed leadership styles for corporations (Dooley et al, 2020). While non-profit organizations struggling to solve societal crisis (Barhate et al, 2021), there is a growing belief that for-profit corporations need to contribute for the betterment of environment and society in addition to their own profits (Ashrafi, Adams, Walker, \& Magnan, 2018; Chia, Kern, \& Neville, 2020; Cheema, Afsar, \& Javed, 2020). These expectations urge corporations to function with moral, ethical, and social obligations and promote equality, diversity, green workplace and contribute to solve issues related to Covid-19 pandemic, climate change, environment pollutions, hunger and poverty.

Simultaneously, HRD is regarded as a field of study and practice that has a fundamental responsibility to improve morality in organizations (Armitage, 2018; Bierema and D'Abundo, 2004; Foote and Ruona, 2008; Russ-Eft and Hatcher, 2003). HRD is defined as a field of theory and practice with an agenda of "human betterment, organizational enhancement and societal development" (McGuire, 2011, p. 1). Foote and Ruona (2008) affirmed that HRD needs to be the major contributor in institutionalization of ethics process, with ethical behavior being ingrained in daily practices, and adopted in the organizational culture, to support morality in the workplace.

Numerous studies have discussed about morals and ethics in human resource discipline. In this study, the term 'ethical' is mentioned to mean a theoretical reflection on morals, whereas 'moral' is used to express a more abstract understanding of right and wrong or good and bad (Pabst, 2018). Nucci (2001) noted that morality refers to "conceptions of human welfare, justice, and rights, which are functions of the inherent features of 
interpersonal relations" (p. 7), and it stems from individuals' concerns underlying effects that one's actions might have on the wellbeing of others. Several scholars affirmed that four psychological processes occur in normal moral functioning: Moral sensitivity, moral judgment, moral motivation, and moral character (Bebeau, Rest, \& Narvaez, 1999; Jordan, 2007; Narvaez \& Vaydich, 2008; Thornberg \& Jungert, 2013).

In this study, our focus is on moral sensitivity, which is the first component of moral functioning model. Thornberg and Jungert (2013) defined moral sensitivity as "an individual's readiness in morally simple situations to recognize moral transgressions and their harming consequences toward others, a sensitivity related to aroused moral emotions such as empathy, sympathy, or guilt" (p. 476). Jordan (2007) described moral sensitivity as "the ability to recognize moral issues in complex situations" (p. 325). In the following sections, we will discuss about moral challenges facing HRD at the individual, organizational, and international levels. The term challenge is identified as a situation where an individual or organization must assess and take a stand in relation to different and conflicting alternatives for action. A moral challenge is present in any situation where the employee or corporation must assess and balance several ethical positions or moral principles that call for different alternatives for action (Pabst, 2018).

\section{Moral Challenges Facing HRD}

\subsection{Moral Challenges in Individual Level}

There have been a variety of studies about deleterious effects of moral challenges in organizations (Alizadeh et al., 2020; Emler, 2019; Feldman, 2019; McGregor, 2019; Plinio et al., 2010). Examples of moral challenges in the workplace include: Accounting fraud, stealing office supplies, and insider trading (Feldman, 2019; McGregor, 2019). Due to a high number of ethical misconducts at workplaces, there is a need to increase moral sensitivity at the individual level (Mintz, 2015). Thornberg and Jungert (2013) noted that moral sensitivity at this level includes dimensions such as 'interpreting others' reactions and feelings, having empathy and role-taking ability, understanding how actions can affect welfare of the self and others, and making inferences from others' behavior and responding appropriately to their reactions" (p. 476). Accordingly, some authors have called for incorporating ethics in HRD practices and strategies (Alizadeh et al, 2020; Armitage, 2017; Kuchinke, 2017; Russ-eft, 2014; Foote \& Ruona, 2008; Hatcher \& Aragon, 2000).

\subsection{Moral Challenges in Organizational and Communal Level}

As Armitage (2017) notes, a significant number of moral challenges are related to practices and goals of organizations. Accordingly, he declared that authors have called for the importance of ethics in organizational government and management (Jaques, 2003) (Lee, 2015). He believes that HRD can play an important role in this regard; a neglect of ethics by HRD and a mere focus on improving efficiency and work performance of employees can result in "enormous harm on individuals, communities, and the environment" (Armitage, 2017, p. 2). He warned that these problems can further harm organizational reputation. Some of the issues at the organizational level are gender and race discriminations (Byrd, 2007), hate crimes (Jacobs \& scott, 2011), wellbeing at work and stress that can lead to mental health issues (Huang et al, 2020), and dubious practices in the hiring and firing of personnel" (Jacobs \& scott, 2011, pp. 2-3). The issue of environmental sustainability of organizations is another important problem in which HRD can play a role (Valentine, 2015).

\subsection{Moral Challenges in International Level}

In the past, corporations could only focus on profit maximization. However, globalization, competitive markets, and governmental laws and regulations pushed multinational corporations to be more socially responsible and act with higher morality. For sustainable development, organizations seek legitimacy in the global market in which they operate (Dunning, 2004). They must build the competency to cope with transformation of the market from a profit driven to a value driven one. Their goal now is not to gain immediate market share, but to win the international competition in a race to build competencies (Kim, 2008). Climate change and energy management are two main areas where corporations find moral challenges at the international level (Kim,2008).

Russ-Eft \& Hatcher (2003) and Short \& Callahan (2005) mention several ethical issues for HRD in the international level, such as low wages and poor working condition of workers of international corporations in poor countries, pollution caused by activities of the international corporations, especially in less developed countries and adverse health side effects on the population of those countries, racial/sexual discrimination, and destruction/undermining of local cultures of developing countries by the culture of dominant world powers. 


\section{Moral Sensitive HRD: Conceptualization and Modelling}

A moral sensitive HRD is supposed to deal with the three levels (i.e., individual, organizational and communal, and international levels) of moral challenges facing HRD. To do so, it requires to be moral realism-based, virtue-oriented, right attentive, environmentally sensitive, context relevant, practical rationality-guided, and cross-culturally tolerant. These significant characteristics of moral sensitive HRD entail a paradigm shift from a classical approach in HRD to a modern morally guided one, which helps us to deal with the three aforementioned levels of moral challenges. We will elaborate on a model based on these six moral theories and concepts, and its functioning as solution providers for the three levels of moral changes (See Figure 1).

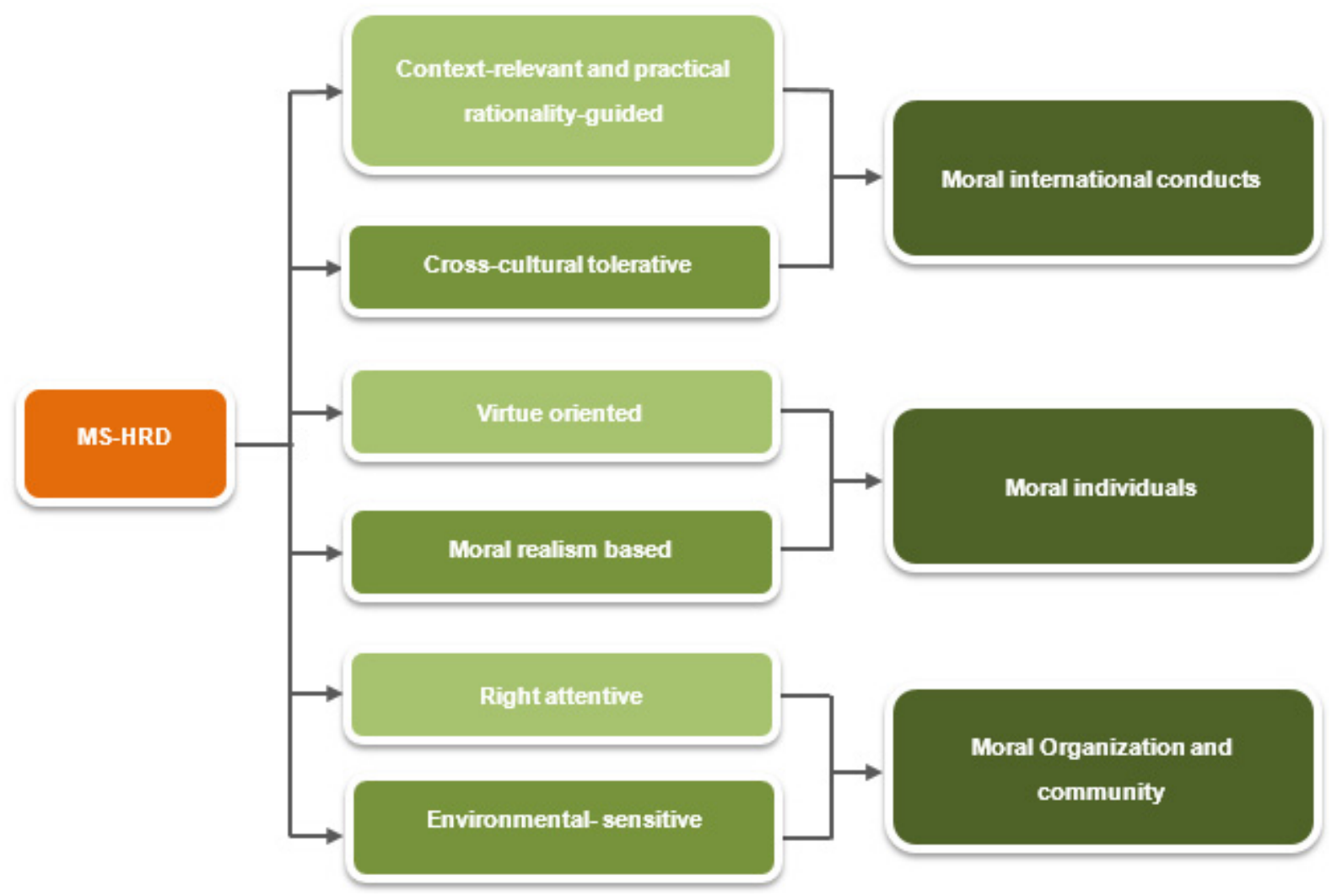

Figure 1. Conceptual model moral sensitive HRD

\subsection{Moral theories for Individual Level}

Two important ethical theories will help HRD tackle the moral challenges it faces in the individual level: moral realism and virtue ethics. Moral realism is the cornerstone of any serious moral inquiry including this paper. Virtue ethics is among the most important and long-lasting moral theories in the history of moral philosophy that provides us with important insights and tools for addressing the problems HRD faces in the individual level. We will also discuss the bearing of these theories on the problems that HRD faces in the individual level (See Figure A1).

\subsubsection{Moral Realism}

Any research on moral education is intelligible only if morality is real. The philosophical position according to which morality is real and objective is called moral realism. For our purposes, moral realism can be defined as a position according to which propositions such as "honesty is good" and "discrimination is bad" are objectively true no matter what anyone thinks about them. This view is commonsensical and enjoys a high degree of pre-theoretic intuitive support. Accordingly, it is no surprise that almost all great philosophers have defended versions of moral realism. Among contemporary philosophers, Boyd (1988), Scanlon (1998), Thomson (2008), and Adams (1999) are examples of distinguished moral realists.

It is a widespread claim that different cultures and civilizations have had radically different moral codes, and this is taken to count against the reality of morality. Moral realists take this claim to be highly exaggerated and have provided vigorous responses to this objection (Enoch, 2009) (Moody-Adams, 1997) (Finnis, 2011). The very 
important point to have in mind is that since morality is like an enquiry about a real, objective matter, moral error is certainly possible, even probable, and this is what makes moral progress possible and moral education necessary.

\subsubsection{Virtue Ethics}

Virtue is among the oldest ethical concepts. Thinkers of very diverse backgrounds such as Plato, Aristotle, Mencius, and Confucius have contemplated it (Hursthouse \& Pettigrove, 2016). Our everyday moral talk and thought is infused with virtue terms. Evaluative terms such as "honest" and "dishonest," "chaste" and "promiscuous", "kind" and "cruel", "lazy" and "hardworking", are all virtue terms that refer to positive or negative character traits. Thus, it seems that a deeper knowledge of virtue would be of great help in understanding and developing our moral lives.

Julia Annas, a prominent contemporary virtue ethicist, defines virtue in the following way: "Virtue is the disposition to do the right thing for the right reason, in the appropriate way honestly, courageously, and so on" (Annas, 2006, p. 516). As she notes, this definition postulates an "affective" and an "intellectual" aspect for a virtuous person. The affective aspect is about the attitudes, such as feelings and motives, with which someone performs the right action. According to virtue ethics, a virtuous person does the right thing with passion and enthusiasm and not with hatred or a sense of compulsion. Someone who does the right thing only for staying out of trouble or to gain some personal benefits and does not care at all about right and wrong in his/her heart is not also a virtuous person (Annas, 2006, p. 517).

The intellectual aspect of virtuousness is captured by the expression "for the right reason" in Annas' definition of virtue. A virtuous person is someone who does the right thing for the right reason, that is, because he/she understands that it is right and good. A soldier who is eager to fight wholeheartedly in any battle upon order cannot be said to have the virtue of courage; he/she is merely fearless. A courageous soldier is the one who fights enthusiastically only in a just war (Hursthouse \& Pettigrove, 2016). To sum up, a virtuous person recognizes good and bad and has a disposition to passionately choose the good.

Annas makes a point that is of utmost importance for the purposes of this paper. She notes that the knowledge and understanding required for grasping and distinguishing good and bad is learned. Acquiring knowledge in ethics requires education. The same is true about the calibration of moral feelings and motivations. It then follows that according to virtue ethics, becoming a virtuous, upright person requires education both of moral truths and moral attitudes and this process starts from childhood. This is a standard doctrine in virtue ethics for both classical and contemporary versions. Aristotle believed that children have to be brought up morally (Kraut, 2018). Hursthouse \& Pettigrove (2016) also note the importance of educating people in virtue for virtue ethicists. In the next section we will see how the framework we sketched here can be used to tackle moral challenges that HRD faces on the individual level.

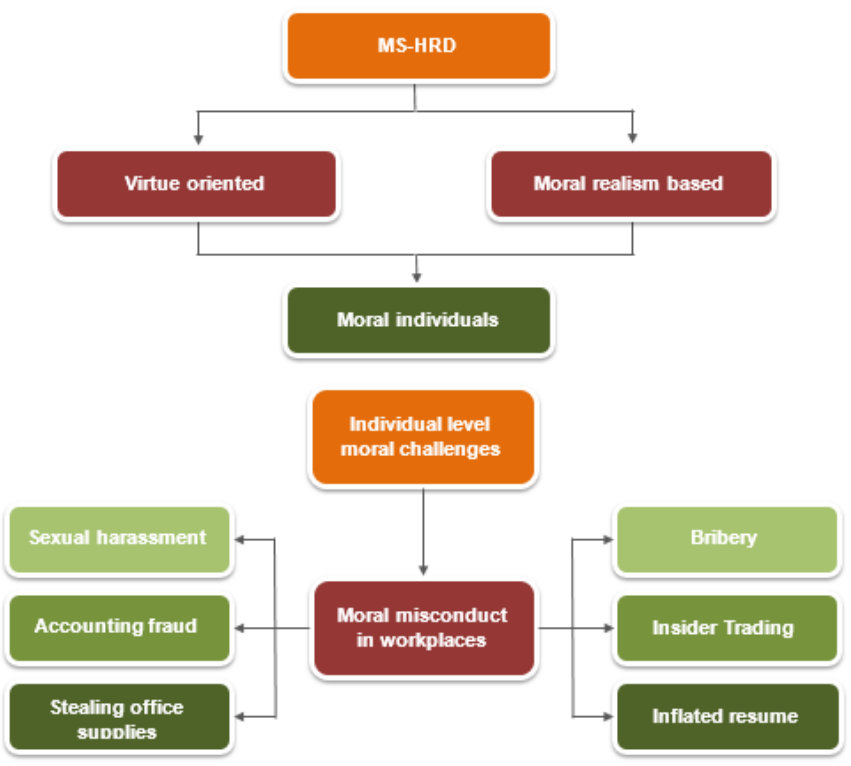

Figure A1. 


\subsubsection{How Theories Help in Individual Moral Problems in HRD}

Kuchinke (2017) points to an obstacle in the way of serious engagement with ethics in HRD. The obstacle is the belief of some scholars that "ethics seems somehow too private, too individual, subjective, relative or weak" (Wray-Bliss 2016, p. 51). Obviously, our discussion of moral realism above can be of great help for eliminating this obstacle. Once HRD theorists and professionals pay attention to the huge pre-theoretical plausibility of moral realism, its overwhelming support among professional philosophers, and the fragility of objections against it, they would be much more motivated to make room for ethics in HRD practices.

The common denominator of the studies that call for an ethically enriched HRD is the call for incorporating ethics into HRD through education and habituation. This, as we illustrated above in our discussion of virtue ethics, is coherent and concordant with precepts of virtue ethics. Becoming a virtuous agent requires moral education and ethical training.

Our discussion of virtue ethics can Also provide insights for what shape that education should take. As Annas (2001) notes, a virtuous person is someone who understands right and wrong, not someone who merely follows rules blindly. It follows that moral education should not take the form of indoctrinating people through bombarding them with moral rules and codes. Rightness and goodness of those rules and codes has to be demonstrated to them in a way that they recognize and internalize the rightness and goodness of those codes and rules. Furthermore, virtuousness requires a harmony between people's affections and understanding. A study by The National Business Ethics Survey, mentioned by Foote and Ruona (2008), reports that a notable number of employees "felt pressured to compromise ethics standards" (p. 293). This feeling of pressure and tendency to do wrongful actions despite knowing the action is wrong shows that those employees do not lack ethical knowledge; they know what is right and wrong. What they lack is harmony between their emotions and desires on the one hand and their beliefs about right and wrong on the other. Accordingly, measures taken for the purpose of moral education should not be solely focused on elevating people's moral knowledge. They should also be highly attentive to cultivating people's moral emotions and motivations. The outcome of moral education would be an increase in virtuousness among the target group and this amounts to a decrease in the prevalence of moral misconducts. such as the ones mentioned in section 1-1.

\subsection{Moral Theories for Organizational and Communal Level}

Most of the moral problems we mentioned in section 1-2 are a result of a neglect of people's rights. Accordingly, in this section we will introduce and explain the notion of a right and its foundations. Furthermore, we introduce environmental ethics in order to address the problem of damage to environment that HRD faces in the organizational and environmental level. We will show how these discussions will help HRD address its moral problems in the organizational and communal level (See figure A2)

\subsubsection{Rights: Conceptualization and Implications}

The notion of right is among the most prevalent notions both in our everyday lives and in our systems of law and government (Wenar, 2020). A rough definition of rights would be "Rights are entitlements (not) to perform certain actions, or (not) to be in certain states; or entitlements that others (not) perform certain actions or (not) be in certain states" (Wenar, 2020). Among the most important and widely mentioned rights are the right to life, right to mental and physical health, and right to equal treatment. As we will see, many moral challenges facing HRD involve the violations of some of these rights.

A way of analyzing rights that is introduced and discussed in Wenar (2020) is known as "the Hohfeldian system" of analysis of rights. The name comes from the American legal theorist Wesley Hohfeld, who introduced this system. According to the Hohfeldian system, simple rights fall into one of the following four categories: Privileges, claims, powers, and immunities. We believe that claims and immunities are the most important ones for HRD. Accordingly, we only mention the definitions of those two categories of simple rights:

Claims: A person, $\mathrm{X}$, has a claim that another person, $\mathrm{Y}$, does something if and only if $\mathrm{Y}$ has a duty to $\mathrm{X}$ to do that action. For example, an employee has a claim that the employer pays her salary and the employer has the duty to do so.

Immunities: one has immunity if and only if other people do not have the power or ability to change her privileges or claims or powers. For example, I have a claim to the health of my body and mind and my employer does not have the power to impose working conditions on me that impair my mental or physical health. This is an immunity that I have vis-à-vis my employer. 
More complex rights like the right to property involve more than one of these simple ones. For example, I have a claim to not allow others to use my laptop and I have the immunity against others who want to take away my privilege or claim or power over it (Wenar, 2020). One feature of rights that is of crucial importance for the purposes of this paper is their special normative force. It is almost agreed upon that rights act as moral trump cards, that is, they often override other non-right concerns that people might have around a certain issue (Wenar, 2020). For example, the goal of increasing the profits of a company or increasing the GDP does not give the stakeholders or the government the permission to deprive the employees or citizens of their rights.

At this stage, a question arises about the foundation and justification of rights and their exalted status in our moral life. Various theories have been proposed by philosophers about this issue. According to one family of theories that Wenar calls "status-based" theories, rights are grounded in certain intrinsic feature of human beings that bestow rights upon them and make them worthy of respect. Among the candidates for such a feature, he mentions "free will, rationality, autonomy, or the ability to regulate one's life in accordance with one's chosen conception of the good life" (Wenar, 2020). The important feature of this view that distinguishes it from one of its prominent rivals is that according to this theory, people's rights are not contingent on good consequences that might arise as a result of respecting rights.

A very prominent proponent of such a theory is the great German philosopher Immanuel Kant. Kant calls the fundamental principle of morality the "Categorical Imperative" which is the source of justification for all moral requirements (Johnson \& Cureton, 2019). The author of this law is the free and autonomous will of a rational agent and it is the existence of this free and autonomous reason in people that makes them worthy of respect, i.e. gives them rights (Johnson \& Cureton, 2019). He provided many formulations of the Categorical Imperative the most famous one of which is the "Formula of Humanity": "So act that you treat humanity, whether in your own person or in the person of any other, always at the same time as an end, never merely as a means." (Kant, 1785; Kerstein, 2019). Wenar (2020) mentions several other proponents of this view among the past and present philosophers.

A famous and rival family of views grounds rights in the optimal distribution of advantages that respecting rights amounts to. Wenar calls this family of views "instrumental" theories of rights. Rule utilitarianism is one such view according to which respecting rights would result in the greatest utility for the greatest number of people (Wenar, 2020). These two families of theories do not exhaust the field. Wenar (2020) mentions other theories too. Adams (1999) and Wolterstorff (2010) propose religious views of human rights that are not mentioned in Wenar (2020). Natural law theories in ethics are another very important and very influential views on the nature of rights. For expositions of those views see Finnis (1998; 2011), and Legge, (2019).

\subsubsection{Environmental Ethics}

Many moral philosophers think about ethical issues that are related to environment and non-human beings inhabiting the environment. Brennan \& Lo (2015) provides an overview of the field of environmental ethics.

One way to approach the question of the ethics of environment is to hold the position that Brennan \& Lo (2015) calls "prudential anthropocentrism". According to this view only human beings are intrinsically valuable but this does not mean that we can treat non-human world in any manner we desire. We have a duty to preserve the environment because a clean and flourishing environment it is necessary for ensuring the wellbeing of human beings. Thus, our duties towards nature according to this view are derived from our duties towards human beings (Brennan \& Lo, 2015).

But another way to look at the issue would be to reject the "strong anthropocentrism" according to which only human beings have intrinsic value (Brennan \& Lo, 2015). As Adams (1999) puts it, there is kind of a consensus that what distinguishes human beings from other creatures and accounts for their exalted moral status is their power of reasoning and their rich mental life. But this can hardly be the entire story about the moral worth of human beings. Among the most egregious crimes that can be committed against a human being are attacks on her body. The horror that is associated with beating up someone or raping someone is testimony that our bodies, which are living animal organisms, are an indispensable part of who we are and are partly responsible for the moral status we have as human beings (Adams, 1999). But if this is the case then what prevents us from respecting the life of a tree or a flower or the mental and physical wellbeing of animals that are capable of feeling pleasure and pain?

Arguments such as the one above are supposed to convince us that while human beings are the most valuable of creatures, non-human creatures have also intrinsic value and accordingly have some rights. This belief would then lead us to revise our destructive behaviors towards nature. 

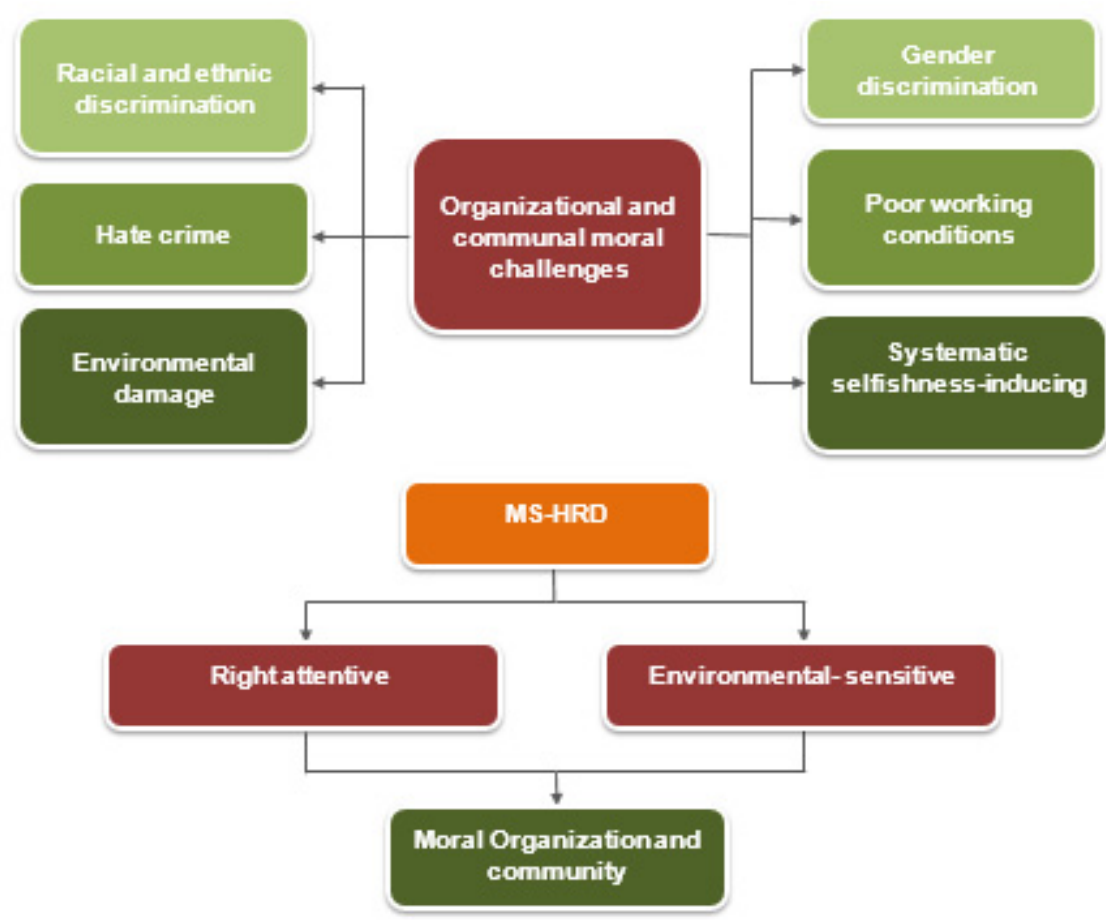

Figure A2.

\subsubsection{How the Theories Help in Organizational and Communal moral problems in HRD}

Most of the problems mentioned in section 1-2 above are results of exclusive and selfish focus of organizations on their profit. In light of our discussion of rights, this exclusive focus is immoral when it violates the rights of people. We have to recall that rights have special normative force and act as moral trump cards. No gain in profits by a business can warrant taking away the right that the workers of that business have to life, health and humane working conditions. Accordingly, organizations have to be informed that exclusive and selfish focus on profits is a vice and also have to be taught about basic human rights and their foundations.

Furthermore, a recognition and internalization of the rights discourse helps fighting racial bigotry and sexist behavior and policy in organizations because as we saw, human rights are not grounded in the skin color or gender of people. People have rights because they are valuable moral agents and people of any race are equally human and equally valuable and thus have equal rights. The same is true about gender equality. Men and women are both equally precious human beings and moral agents that their rights have to be respected. Accordingly, any gender-based discrimination between people by organizations is immoral and has to be resisted.

Finally, attention to the intrinsic value of non-human creatures can restrain the organizations' destructive activities towards nature and lead them to a more environmentally sustainable path. But even if they don't buy the argument in favor of the intrinsic value of nature, they can be taught about prudential anthropocentrism. They have to know that destroying the environment will ultimately result in the destruction of themselves and their loved ones and maybe the whole human race.

\subsection{Moral Theories for International Level}

In this section we are going to discuss the importance of context in ethics through introducing natural law theory which is an important and influential ethical theory. We will also introduce and discuss the notion of toleration. As we will show, these discussions will be helpful in addressing the problem of cultural diversity and the importance of local cultures that HRD faces in the international level (See figure A3.)

\subsubsection{Morality in Context and Practical Rationality}

According to a very influential conception of what morality is, general moral principles such as "you should obey the law" are essential to morality. According to variants of this view, moral principles are either absolutely decisive in determining whether certain action is right or wrong or they give us strong reasons in every context to act in a certain way. Call this view "generalism" (Dancy, 2017). On the other hand, there is a view, called 
"particularism", that denies the essentiality of universal principles to morality. Proponents of this view believe that there are different moral reasons in different contexts and no moral principle is either absolute or reason giving in every context. For example, they believe that in the case of an unjust racist law, the fact that an action is against the law not only does not count against doing it, but it rather gives us reason to do it! (Dancy, 2017).

This is a very complex philosophical debate that cannot be resolved here. Also given the fact that we have already introduced Kant's categorical imperative as a general moral rule, we are not embracing all that the particularist says. But we believe that the particulaist insight about the importance of context in morality is very plausible and useful for addressing some of the problems that HRD faces in the international level. Accordingly, we believe that taking another look at Aristotlian views of morality would be helpful for our purposes because although those views do not reject moral principles, they contain certain particularist elements.

According to a very influential Aristotlian view in morality called "Natural Law Theory", the foundation of morality is based on certain basic goods that are constituents of good and flourishing human life. These basic goods include life, knowledge, rationality, play, aesthetic experience, and friendship and communal life. The good of rationality is important in particular since the principles of practical rationality guide our pursuit of these goods. Examples of principles of practical rationality are "one have to have a coherent plan of life", and "one should not arbitrarily prefer one value over the other" (Finnis, 2011). People should, compatible with principles of practical rationality, purse, respect, and promote these values in their lives and lives of other people and social institutions have to be designed in a way that fosters the pursuit and promotion of these goods (Murphy, 2019; Finnis, 2011; Finnis, 2020). People have a right to these basic goods no matter what their race, gender, and nationality is and actions, practices, and organizations that hurt these values are and should not be tolerated.

The important thing that has to be noted here is that the basic goods and the principles of practical rationality are cashed out in broad and general terms. Also, according to some very influential versions of natural law theory, no basic good is superior to the other. They are all equally good and basic (Finnis, 2011). This leaves a lot of room for flexibility in choosing our lives. All life plans that are cognizant of the basic goods and compatible with principles of practical rationality are equally good. For example, an agricultural society and an industrial society are equally good in so far that they pursue these goods and do not destroy any one of them. The fact that they pursue them in different ways does not have a bearing on their goodness. Different cultures put more emphasis on different basic goods. This is inevitable given the shortness and complexity of life. What matters is that all these goods have to be respected and pursued in different degrees. But the fact that some cultures pursue art more than knowledge or vice versa does not count against those cultures in so far as that pursuit isn't a result of wrongful neglect and contempt for art or knowledge (Finnis, 2011).

\subsubsection{Toleration: Conceptualization and Implications}

Toleration is among the most important ethical notions that is necessary for sustainability of any society and community, be it a family, city, country, or a corporation or organization. Toleration becomes important in situations in which people disagree about certain issues. The issues might be very important but this does not mean that tolerance has no limits. Certain false and dangerous views are simply intolerable (Forst, 2017). For example, the false and dangerous views of racists are not tolerable but people of different faiths can and should tolerate one another even though they disagree on certain issues in their worldviews.

There are various conceptions of toleration. In this paper we introduce three of them that would be most beneficial in addressing the problems HRD faces:

a) Coexistence Conception: according to this conception, people of different cultures and belief systems that have a certain common goal choose to tolerate each other as a means of avoiding conflict and efficiently achieving that goal (Forst, 2017).

b) Respect Conception: According to this conception, toleration should not be thought of merely as a pragmatic tool for sustaining peace and achieving their goals. People have also to think of their interlocutors as respectable human beings whose conscience and autonomy has to be respected. It follows from this attitude that people should try to avoid conflict and tolerate those beliefs of the opposite party with which they disagree out of respect for their interlocutors (Forst, 2017).

c) Esteem Conception: This conception goes a step further than the respect conception. According to this conception people not only have to tolerate other worldviews out of respect for the adherents of those worldviews, but also because there is moral value in other worldviews even though we are not eager to embrace and accept all of the contents and details of those views (Forst, 2017). 


\subsubsection{The Limits of Toleration}

As we noted, toleration is not limitless. Here we want to suggest some criteria for the limits of toleration. Kant's formula of humanity that we mentioned in the previous section can be a very good criterion. Here's the formula again: "So act that you treat humanity, whether in your own person or in the person of any other, always at the same time as an end, never merely as a means." (Kant, 1785; Kerstein, 2019). If we adopt this formula as a criterion for toleration then actions, beliefs, and attitudes that fail to respect the humanity of people in the appropriate way will be intolerable. The exploitation of workers and subordinates by the managers of organizations would be intolerable according to this criterion. Also, natural law theory provides us with valuable resources for determining the limits of toleration. People have rights to basic goods and any action and practice that prevents them from achieving those goods cannot be tolerated.

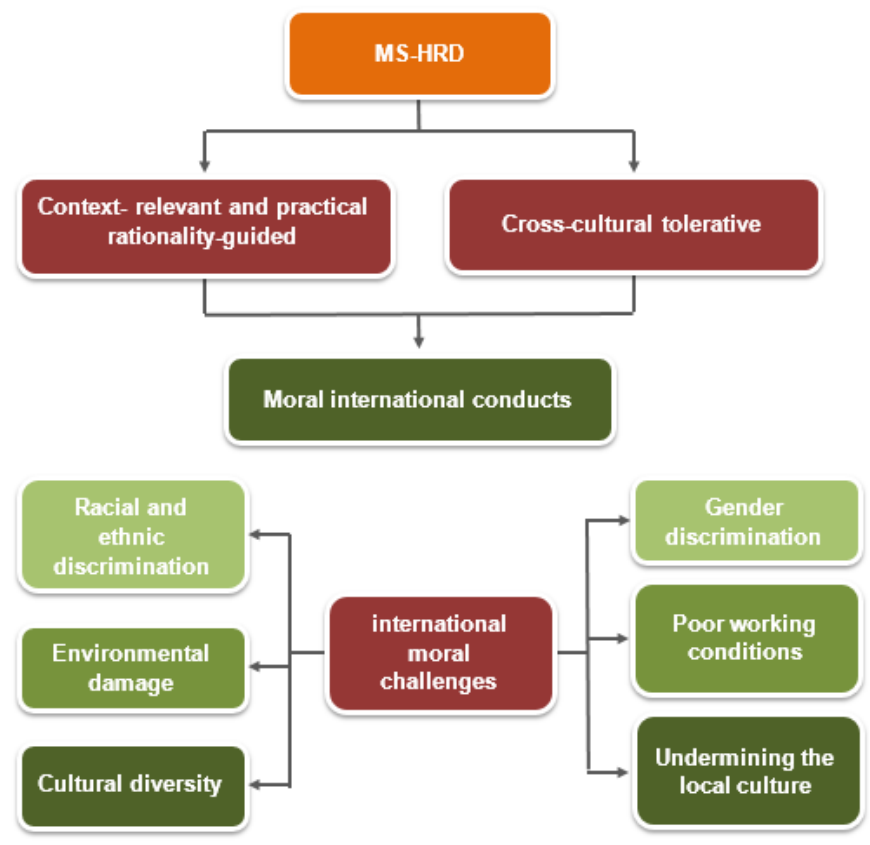

Figure A3.

\subsubsection{How the Theories Help in International Moral Problems in HRD}

The first three of the four problems in the international level mentioned in section 1-3 are similar to the ones in the organizational and communal level. Accordingly, it is obvious that our discussion of rights and environmental ethics have a direct bearing on these problems too. Workers are entitled to humane working conditions and wages that can support their rights to a decent and healthy life and the fact that they are foreign workers of an international company does not change that fact at all. People have equal rights no matter what their nationality, race or gender is and corporations have to be committed to respecting these rights. Regarding the pollution of environment, recall that this destruction of nature is a destruction of something precious and valuable and so is morally wrong. In addition to this, it threatens the lives of people living there and undermines their rights to a healthy life and accordingly cannot be tolerated. We should always have in mind that rights are moral trump cards and are superior to the profit motif of corporations.

Even though the problem about cultural diversity can be a challenge in the previous two levels that we discussed it is more urgent at the international level because cultural diversity is much starker in the international level than domestic levels. People in different countries have different cultures, traditions, religions, and worldviews. Corporations and organizations that want to work at the international level have to be highly attentive to this fact if they want to be successful. We believe that our discussion of the importance of context the three conceptions of toleration and the criteria we introduced for the limits of toleration can help HRD specialists engage this problem in a more fruitful way.

There might be certain elements in the cultures and traditions of certain countries that are not tolerable. As we noted above, these would be practices and attitudes that either fail to respect the humanity of people as an end or they are harmful to the basic human goods such as life, knowledge, and play. Racist and sexist attitudes and 
institutions and harmful practices such as child labor are the most important examples of these intolerable phenomena. We think corporations and organizations are within their rights not to tolerate those practices and HRD practitioners can try to engage with the people and authorities of those countries for the purpose of weakening those immoral and harmful practices. In fact, Marquardt \& Berger (2003) call for the engagement of HRD specialists in the "cultural, and spiritual development of people around the world".

But there are also a whole host of cultural elements in different countries that are absolutely tolerable. The religion and deeply rooted moral beliefs of a country, their dressing and eating habits, their traditions and the forms of arts they have developed are all examples of such elements. These practices are in general cognizant of basic goods introduced above and do not flout the principles of practical rationality. These are different ways of pursuing human goods that are instantiated in different contexts and situations. Thus, given out discussion of the importance of context in morality and the flexibility of moral life, there is no reason to be hostile towards them. Indeed, there is reason to promote them in order to promote the richness and diversity of human life and human experience.

Furthermore, paying serious attention to the respect conception and the esteem conception of toleration mentioned above would help International organizations and corporations to engage with these differences. It follows from the respect conception of toleration that these are the beliefs and traditions of human beings that are their moral equals and have to be respected because of the respect that those people are entitled to. It follows from the esteem conception of toleration that even if an international organization does not accept all the cultural and traditional values and practices of a country, there certainly are certain elements in those traditions are valuable and acceptable. Accordingly, the practices with which they disagree can be tolerated out of respect for practices that are acceptable and valuable.

Finally, if a corporation or organization is not moved by the respect and esteem conceptions of toleration, it has to take note of the coexistence conception of toleration. Failing to tolerate and respect the deep seated beliefs and cultural heritage of a people will most likely amount to backlash and conflict. Accordingly, if an international corporation wants to be successful it has no choice but to tolerate certain elements of the culture of the host country.

\section{Implementation of morality in HRD}

Several studies have emphasized the effectiveness of ethics courses that teaching ethics to people does have a positive effect on their ethical thinking and behavior (Alizadeh et.al., 2020; Tormo-Carbó et al., 2016; Lau, 2010; Saat et al., 2010). This is absolutely concordant with the Aristotelian view of morality and moral habituation that was introduced and discussed earlier. Accordingly, one effective way to use the moral theories and concepts introduced in this paper is to include them in a course on ethics. Even ethical training workshops that are relatively shorter in their duration than typical ethics courses seem to have a significant impact on the ethical knowledge of participants (Ajuwon \& Kass, 2008).

Some studies report that participants in the ethics courses have concerns about those courses that in their views have reduced their effectiveness. The concerns are about the significance of the contents of the courses and their relevance to actual moral problems that the students faced. There were also concerns about the effectiveness of teaching strategies (Saini, 2019; Alizadeh et.al, 2020). These are all very important concerns and we have tried to address them in this paper. First, the moral theories and concepts that we introduced are all inspired by the problems mentioned in the works of HRD scholars so that there is a continuity between the problems that HRD faces and the moral theories and concepts that we introduce. Second, we have used the works of distinguished professional moral philosophers in our exposition of moral theories and concepts and have tried to have a deeper and more foundational discussion of the ethical theories and concepts so that the content is more intellectually challenging.

While the traditional format of education through lectures is the most familiar way, there can be alternative methods that can be used for moral education in addition to lectures. LeClair \& Ferrell (2000) discuss why we should search for new methods of moral training and what considerations we have to have for designing these methods. Fischbach (2014) introduces the use of graphic novels as a more effective method for ethical training than written novels. Jagger et. al. (2016) introduces a 3D immersive game for business ethics education. Afroogh et al. (2021) suggests an empathic design for community resilience in engineering.

Another relatively novel method that can be used for moral education is "nudging". Originally put forward by Cass Sunstein and Richard Thaler (2003), the basic idea of nudging is that we can compensate for people's, often, bad decision making by orchestrating their choices in a way that they would make choices that are in their benefit (Dworkin, 2020). For example, in order to help people have a more healthy diet, shelves in food stores 
can be arrange in a way that the stuff that are most visible to customers are the most healthy ones. This would nudge people to choose more healthy foods without inserting and visible coercive force upon them (Dworkin, 2020). According to Sunstein, the following are all nudges: "reminders, warnings, a GPS, disclosure of the interest rate of a bank card, any information about what people like you do, simplification of government forms, default rules, subliminal messages urging people to eat healthy food." (Dworkin, 2020). Engelen et al. (2018) suggests that nudging, used in tandem with narratives about morally exemplar individuals, can be an effective strategy in moral education. To give an example that is more relevant to HRD, Putting reminders and warnings about the moral code of the organization or about the contents of the ethics courses that employees are taking would be an act of nudging to raise the effectiveness of those courses promote the moral awareness of the employees.

In addition to ethics as a course, Alizadeh et al. (2020) mentions another four important notions that have to be taken into consideration in any fruitful engagement of HRD with ethics: ethical culture, code of ethics, corporate social responsibility, and effective communication.

Several studies suggest that the ethical culture of a workplace impacts the ethical decision-making of people in the workplace (Alizadeh et. al., 2020; Victor and Cullen ,1988; Treviño et al., 1998; Newman et. al, 2017; Simha \& Cullen, 2012; Schminke et al., 2007). This is indeed a vindication of the Aristotlian insight that one becomes a virtuous individual by practicing through living a virtuous life. Someone who lives in an environment in which wrong actions are not appropriately discouraged and punished and right actions are not appropriately promoted and rewarded, eventually either loses her sense of right and wrong or loses motivation And passion for doing the right thing or maybe both. Our discussion of virtue ethics provides a philosophical foundation and explanation for empirical studies on moral climate and also provides guidance on what a virtue-friendly environment is supposed to be.

Codes of ethics can be effective tools in guiding people in their moral decision making and fostering a morally healthy ethical environment (Alizadeh et al, 2020; Stevens, 2008; McKinney et al., 2010). Accordingly, they are indispensable parts of people's moral education. Of course, as has been noted, they have limited influence on and of themselves and have to be joined with vigorous ethical training so that the subjects develop the ability to engage them and try to implement them in their ethical life and decision making (Alizadeh et.al, 2020). In addition to helping in the task of designing content for ethics training courses, our theoretical discussions about ethics in this paper can be beneficial in designing more philosophically informed codes of ethics that can be used in international contexts as well as the communal and individual contexts (Afroogh, 2019; Afroogh 2021).

Our discussion of environmental ethics will be of great use for increasing corporate social responsibility which, as we said earlier, is an important factor in creating a healthy moral climate (Alizadeh et. al., 2020; Hansen et al., 2016). Effective communication is important for moral education as a trust building and knowledge sharing, and community building mechanism (Alizadeh et. al., 2020; DuFrene \& Lehman, 2014; Dehghan-Chaleshtori, M. \& Zhang, J. 2020; Akbari et al. 2020; Coleman et al. 2019). Of course it has to happen in a context in which agents are morally informed and an effective code of conduct is cherished by all.

Finally, tackling these problems, especially in the organizational and international level, requires some changes and adjustments in the laws and policies of the country. Accordingly, HRD needs a more robust engagement with politicians and policy makers. Marquardt \& Berger (2003), for example, calls for such engagement in the international level.

\section{Conclusion}

HRD needs to engage with ethics. This paper was an attempt to show how theories and concepts developed by professional moral philosophers can be brought to bear on actual moral problems and issues that HRD faces. Reviewing the literature on this topic, we suggested that ethical problems of HRD can be divided into three categories and supplied moral theories and concepts that can be used to address those problems and morally enrich the HRD discipline.

As a first step, we defended the reality of morality by introducing and defending moral realism. We then introduced virtue theory as an ancient and effective framework for moral thinking and moral education that can be used to address ethical problems HRD faces in the individual level.

Much of the problems arising in the organizational and communal level are a result of putting profit above people and ignoring people's rights. Accordingly, we introduced the notion of rights and illustrated the exalted normative force of rights. Paying attention to rights of people and the grounds of those rights helps greatly in overcoming exploitation of employees and opposing racial and gender discrimination. We further discussed the 
moral significance of environment by introducing environmental ethics. This discussion helps HRD become more environmentally sustainable and socially responsible.

The problem of cultural diversity and protection of regional cultures arises in the international level. By emphasizing the importance of context in ethics and introducing the notion of tolerance, we provided a way for HRD to try to tackle this problem.

Finally, we supplied some strategies for implementing the moral theories and concepts in HRD practice. We emphasized the role of moral education and showed how our ethical discussion can provide a theoretical justification for moral education. We also introduced the notion of nudging and suggested that it can be used for moral education and habituation of people. We also emphasized the importance of the following factors for building a moral sensitive HRD: ethical culture, code of ethics, corporate social responsibility, and effective communication.

While we tried to introduce moral theories and concepts in a relatively deep and serious manner, more effort is required for making HRD ethical sensitive. There might be moral issues and problems that we did not discuss here and have to be studied. Furthermore, a much deeper engagement with the literature of moral philosophy is required than what we provide in this paper.

As we tried to establish, moral education is indispensable for moral sensitive HRD. Accordingly, research into novel strategies for efficient moral education is necessary. We put forward some studies that propose novel methods for moral education but more needs to be said. Also, as we noted, moral sensitive HRD in the communal and international level requires engagement with lawmakers and government authorities; both domestic and foreign. This is a very important issue that further HRD research needs to reflect on.

\section{References}

Adams, R. M. (1999). Finite and Infinite Goods. New York: Oxford University Press.

Afroogh, S. (2019). Contextual Reason and Rationality. Texas A \& M University: College Station, TX, USA.

Afroogh, S. (2021). A Contextualist Decision Theory.

Afroogh, S., Esmalian, A., Donaldson, J., \& Mostafavi, A. (2021). Empathic Design in Engineering Education and Practice: An Approach for Achieving Inclusive and Effective Community Resilience. Sustainability, 13(7), 4060. https://doi.org/10.3390/su13074060

Ajuwon, A. J., \& Kass, N. (2008). Outcome of a research ethics training workshop among clinicians and scientists in a Nigerian university. BMC Medical Ethics, 9(1), 1-9. https://doi.org/10.1186/1472-6939-9-1

Akbari, A., Solis, C. R., Jafari, R., \& Mortazavi, B. J. (2020). Using intelligent personal annotations to improve human activity recognition for movements in natural environments. IEEE Journal of Biomedical and Health Informatics (JBHI), 24(9), 2639-2650. https://doi.org/10.1109/JBHI.2020.2966151

Alizadeh, A., Dirani, K. M., \& Qiu, S. (2020). Ethics, code of conduct and ethical climate: implications for human resource development. European Journal of Training and Development. https://doi.org/10.1108/EJTD-04-2020-0077

Annas, J. (2006). Virtue Ethics. In David Copp (Ed.), The Oxford Handbook of Ethical Theory (pp. 515-536). Oxford: Oxford University Press.

Armitage, A. (2017). Is HRD in need of an ethics of care? Human Resource Development International. https://doi.org/10.1080/13678868.2017.1366176

Ashrafi, M., Adams, M., Walker, T. R., \& Magnan, G. (2018). How corporate social responsibility can be integrated into corporate sustainability: a theoretical review of their relationships. International Journal of $\begin{array}{lllll}\text { Sustainable Development \& World Ecology, 25(8), } & \text { 672-682. }\end{array}$ https://doi.org/10.1080/13504509.2018.1471628

Barhate, B., Hirudayaraj, M., Gunasekara, N., Ibrahim, G., Alizadeh, A., \& Abadi, M. (2021). Crisis Within a Crisis: Migrant Workers' Predicament During COVID-19 Lockdown and the Role of Non-profit Organizations in India. Indian Journal of Human Development, 1-14. https://doi.org/10.1177/0973703021997624

Boyd, R. (1988). How to Be a Moral Realist. in Essays on Moral Realism, G. Sayre-McCord (Eds.).

Brennan, A., \& Lo, Y. (2020). Environmental Ethics. In Edward N. Zalta (Ed.), The Stanford Encyclopedia of Philosophy. 
Byrd, M. (2007). Educating and developing leaders of racially diverse organizations. Human Resource Development Quarterly, 18(2), 275-279. https://doi.org/10.1002/hrdq.1203

Cheema, S., Afsar, B., \& Javed, F. (2020). Employees' corporate social responsibility perceptions and organizational citizenship behaviors for the environment: The mediating roles of organizational identification and environmental orientation fit. Corporate Social Responsibility and Environmental Management, 27(1), 9-21. https://doi.org/10.1002/csr.1769

Chia, A., Kern, M. L., \& Neville, B. A. (2020). CSR for Happiness: Corporate determinants of societal happiness as social responsibility. Business Ethics: A European Review, 29(3), 422-437. https://doi.org/10.1111/beer.12274

Coleman, N., Esmalian, A., \& Mostafavi, A. (2019). Equitable resilience in infrastructure systems: Empirical assessment of disparities in hardship experiences of vulnerable populations during service disruptions. Natural Hazards Review, 21. https://doi.org/ 10.1061/(ASCE)NH.1527-6996.0000401

Copp, D. (Ed.). (2005). The Oxford handbook of ethical theory. Oxford University Press.

Copp, D., \& Sobel, D. (2004). Morality and virtue: An assessment of some recent work in virtue ethics. Ethics, $114(3), 514-554$.

Dancy, J. (2017). Moral Particularism. In Edward N. Zalta (Ed.), The Stanford Encyclopedia of Philosophy.

Dehghan-Chaleshtori, M., \& Zhang, J. (2020). Dialogic Interaction of Language Learners in a Knowledge Building Community. In Gresalfi, M. and Horn, I. S. (Eds.), The Interdisciplinarity of the Learning Sciences, 14th International Conference of the Learning Sciences (ICLS) 2020 (Volume 2, pp. 681-684). Nashville, Tennessee: International Society of the Learning Sciences.

Dooley, L. M., Alizadeh, A., Qiu, S., \& Wu, H. (2020). Does Servant Leadership Moderate the Relationship between Job Stress and Physical Health? Sustainability, 12(16), 6591. https://doi.org/10.3390/su12166591

Driver, J. (2001). Uneasy Virtue. New York: Cambridge University Press.

DuFrene, D. D., \& Lehman, C. M. (2014). Navigating change: employee communication in times of instability. Business and Professional Communication Quarterly, 77(4), 443-452. https://doi.org/10.1177/2329490614544736

Dunning, J. H. (Ed.). (2004). Making globalization good: The moral challenges of global capitalism. Oxford University Press.

Dworkin, G. (2020). Paternalism. In Edward N. Zalta (Ed.), The Stanford Encyclopedia of Philosophy. Retrieved from http://www.plato.stanford.edu/archives/fall2020/entries/paternalism

Emler, N. (2019). Seven moral challenges of leadership. Consulting Psychology Journal: Practice and Research, 71(1), 32-46. https://doi.org/10.1037/cpb0000136

Engelen, B., Thomas, A., Archer, A., \& Van de Ven, N. (2018). Exemplars and nudges: Combining two strategies for moral education. Journal of Moral Education, 47(3), 346-365. https://doi.org/10.1080/03057240.2017.1396966

Enoch, D. (2009). How is moral disagreement a problem for realism? The Journal of Ethics, 13(1), 15-50. https://doi.org/10.1007/s10892-008-9041-z

Ethics Resource Center. (2005). National Business Ethics Survey 2005: How employees view ethics in their organizations. Retrieved from http://www.erc.org

Feldman, Y. (2019). Companies need to pay more attention to everyday unethical behavior. Harvard Business Review. Retrieved

from https://hbr.org/2019/03/companies-need-to-pay-more-attention-toeveryday-unethical-behavior

Finnis, J. (1998). Aquinas: moral, political, and legal theory. Oxford University Press.

Fischbach, S. (2015). Ethical efficacy as a measure of training effectiveness: An application of the graphic novel case method versus traditional written case study. Journal of Business Ethics, 128(3), 603-615. https://doi.org/10.1007/s10551-014-2118-7

Foot, P. (2001). Natural Goodness. Oxford, Clarendon Press.

Foote, M. F., \& Ruona, W. E. (2008). Institutionalizing ethics: a synthesis of frameworks and the implications for HRD. Human Resource Development Review, 7(3), 292-308. 
Forst, R. (2017). Toleration. In Edward N. Zalta (Ed.), The Stanford Encyclopedia of Philosophy. Retrieved from: plato.stanford.edu/archives/fall2017/entries/toleration

Hansen, S. D., Dunford, B. B., Alge, B. J., \& Jackson, C. L. (2016). Corporate social responsibility, ethical leadership, and trust propensity: a multi-experience model of perceived ethical climate. Journal of Business Ethics, 137(4), 649-662. https://doi.org/10.1007/s10551-015-2745-7

Hatcher, T., \& Aragon, S. R. (2000). A code of ethics and integrity for HRD research and practice. Human Resource Development Quarterly, 11(2), 179.

Heineman, B. (2007). Avoiding integrity land mines: An inside look at how GE worked to build a culture that sustains both high performance and high integrity. Harvard Business Review, 4, 1-8.

Huang, N., Qiu, S., Alizadeh, A., \& Wu, H. (2020). How incivility and academic stress influence psychological health among college students: The moderating role of gratitude. International journal of environmental research and public health, 17(9), 3237. https://doi.org/10.3390/ijerph17093237

Hurka, T. (2001). Virtue, Vice, and Value. Oxford: Oxford University Press.

Hursthouse, R., \& Pettigrove, G. (2018). Virtue Ethics. In Edward N. Zalta (Ed.), The Stanford Encyclopedia of Philosophy. Retrieved from: plato.stanford.edu/archives/win2018/entries/ethics-virtue

Jacobs, J. L., \& Scott, C. L. (2011). Hate crimes as one aspect of workplace violence: Recommendations for HRD. Advances in Developing Human Resources, 13(1), 85-98. https://doi.org/10.1177/1523422311410653

Jagger, S., Siala, H., \& Sloan, D. (2016). It's all in the game: A 3D learning model for business ethics. Journal of business ethics, 137(2), 383-403. https://doi.org/10.1007/s10551-015-2557-9

Jaques, E. (2003). Ethics for Management. Management Communication Quarterly, 17(1), 136-142. https://doi.org/10.1177/0893318903253445

Johnson, R., \& Cureton, A. (2019). Kant's Moral Philosophy. In Edward N. Zalta (Ed.), The Stanford Encyclopedia of Philosophy.

Kant, I. (1785). Grundlegung zur Metaphysik der Sitten. Translated as Groundwork of the Metaphysics of Morals in Kant 1996, 37-108.

Kerstein, S. (2019). Treating Persons as Means. In Edward N. Zalta (Ed.), The Stanford Encyclopedia of Philosophy.

Kim, C. H. (2008). Climate Change: Business Challenge or Opportunity? In EKC2008 Proceedings of the EU-Korea Conference on Science and Technology (pp. 437-442). Springer, Berlin, Heidelberg.

Kraut, R. (2018). Aristotle's Ethics. In Edward N. Zalta (Ed.), The Stanford Encyclopedia of Philosophy.

Kuchinke, K. P. (2017). The ethics of HRD practice. Human Resource Development International, 20(5), 361-370. https://doi.org/10.1080/13678868.2017.1329369

Lau, C. L. (2010). A step forward: ethics education matters! Journal of Business Ethics, 92(4), 565-584. https://doi.org/10.1007/s10551-009-0173-2

LeClair, D. T., \& Ferrell, L. (2000). Innovation in experiential business ethics training. Journal of Business Ethics, 23(3), 313-322.

Lee, M. (2015). The History, Status and Future of HRD. In R. Poell, T. Rocco, and R. Gene (Eds.), The Routledge Companion to Human Resource Development (pp. 3-12). London: Routledge.

Legge, D. (2019). Do Thomists Have Rights? Nova et vetera, 17(1), 127-147.

Marquardt, M., \& Berger, N. O. (2003). The future: Globalization and new roles for HRD. Advances in Developing Human Resources, 5(3), 283-295. https://doi.org/10.1177/1523422303254668

McGregor, J. (2019). More CEOs were forced out for ethical lapses in 2018 than poor financial performance. The Washington Post. Retrieved from http://www.washingtonpost.com/business/2019/05/15/more-ceos-were-forced-out-ethical-lapses-than-poorfinancial-performance/

McGuire, D. (2011). Foundations of human resource development. In D. McGuire \& K. M. Jorgensen (Eds.), Human resource development: Theory and practice (pp. 1-11). London, England: SAGE.

McKinney, J. A., Emerson, T. L., \& Neubert, M. J. (2010). The effects of ethical codes on ethical perceptions of actions toward stakeholders. Journal of Business Ethics, 97(4), 505-516. 
https://doi.org/10.1007/s10551-010-0521-2

Mintz, S. (2015). Unethical behaviors in the workplace. Retrieved from http://www.workplaceethicsadvice.com

Moody-Adams, M. (1997). Fieldwork in familiar places: Morality, culture and philosophy. Cambridge: Harvard University Press.

Murphy, M. (2019). The Natural Law Tradition in Ethics. In Edward N. Zalta (Ed.), The Stanford Encyclopedia of Philosophy.

Newman, A., Round, H., Bhattacharya, S., \& Roy, A. (2017). Ethical climates in organizations: a review and research agenda. Business Ethics Quarterly, 27(4), 475-512. https://doi.org/10.1017/beq.2017.23

Nucci, L. P. (2001). Education in the moral domain. Cambridge: Cambridge University Press.

Pabst, K. (2018). Considerations to Make, needs to Balance: Two Moral Challenges Museum Employees Face When Working with Contested, Sensitive Histories. Museum International, 70(3-4), 84-97.

Parke, K., \& Funk, C. (2017). Women are more concerned than men about gender discrimination in tech industry. Pew Research Center. Retrieved from https://www.pewresearch.org/fact tank/2017/10/10/women-are-more-concerned-than-men-about-gender-discrimination-in-tech-industry/

Plinio, A. J., Young, J. M., \& Lavery, L. M. (2010). The state of ethics in our society: a clear call for action. International Journal of Disclosure and Governance, 7(3), 172-197. https://doi.org/ 10.1057/jdg.2010.11

Russ-Eft, D. (2014). Morality and Ethics in HRD. In N. Chalofsky, T. Rocco, and M. L. Morris (Eds.), Handbook of Human Resource Development (pp. 510-524). San Francisco: Jossey-Bass.

Russ-Eft, D., \& Hatcher, T. (2003). The issue of international values and beliefs: The debate for a global HRD code of ethics. Advances in Developing Human Resources, 5(3), 296-307. https://doi.org/10.1177/1523422303254670

Saat, M. M., Porter, S., \& Woodbine, G. (2010). The effect of ethics courses on the ethical judgement making ability of Malaysian accounting students. Journal of Financial Reporting and Accounting, 8(2), 92-109. https://doi.org/10.1108/19852511011088361

Saini, D. (2019). Teaching ethics to future managers: encouraging and discouraging impulses. South Asian Journal of Business and Management Cases, 8(3), 276-286. https://doi.org/10.1177/2277977919860283

Scanlon, T. M. (1998). What We Owe to Each Other. Cambridge, MA: Harvard University Press.

Schminke, M., Arnaud, A., \& Kuenzi, M. (2007). The power of ethical work climates. Organizational Dynamics, 36(2), 171-186. https://doi.org/10.1016/j.orgdyn.2007.03.005

Short, D. C., \& Callahan, J. L. (2005). Would I Work for a Global Corporation? and Other Ethical Questions for HRD. Human Resource Development International, 8(1), 121-125. https://doi.org/10.1080/1367886042000338281

Simha, A., \& Cullen, J. R. (2012). Ethical climates and their effects on organizational outcomes: Implications from the past and prophecies for the future. Academy of Management Perspectives, 26(4), 20-34. https://doi.org/10.5465/amp.2011.0156

Sims, R. R. (2003). Ethics and corporate responsibility: Why giants fall. Westport, CT: Greenwood.

Stevens, B. (2008). Corporate ethical codes: effective instruments for influencing behavior. Journal of Business Ethics, 78(4), 601-609. https://doi.org/10.1007/s10551-007-9370-z

Sunstein, C. R., \& Thaler, R. H. (2003). Libertarian paternalism is not an oxymoron. The University of Chicago Law Review, 1159-1202.

Thomson, J. J. (2008). Normativity. Chicago: Open Court.

Thornberg, R., \& Jungert, T. (2013). Bystander behavior in bullying situations: Basic moral sensitivity, moral disengagement and defender self-efficacy. Journal of adolescence, 36(3), 475-483. https://doi.org/10.1016/j.adolescence.2013.02.003

Tormo-Carb, O. G., Seguí-Mas, E., \& Oltra, V. (2016). Accounting ethics in unfriendly environments: the educational challenge", Journal of Business Ethics, 135(1), 161-175. https://doi.org/10.1007/s10551-014-2455-6

Treviño, L. K., Butterfield, K. D., \& McCabe, D. L. (1998). The ethical context in organizations: influences on employee attitudes and behaviors. Business Ethics Quarterly, 8(3), 447-476. 
Valentin, C. (2015). Greening HRD: Conceptualizing the triple bottom line for HRD practice, teaching, and research. Advances in Developing Human Resources, 17(4), 426-441. https://doi.org/10.1177/1523422315599621

Victor, B., \& Cullen, J. B. (1988). The organizational bases of ethical work climates. Administrative Science Quarterly, 33(1), 101-125.

Wenar, L. (2020). Rights. In Edward N. Zalta (Ed.), The Stanford Encyclopedia of Philosophy.

Wolterstorff, N. (2010). Justice: Rights and wrongs. Princeton University Press.

Wray-Bliss, E. (2016). Ethical Philosophy, Organization Studies and Good Suspicions. In R. Mir, H. Willmott, and M. Greenwood (Eds.), The Routledge Companion to Philosophy in Organization Studies, (pp. 51-65). Milton Park, Abington, UK: Routledge.

\section{Copyrights}

Copyright for this article is retained by the author(s), with first publication rights granted to the journal.

This is an open-access article distributed under the terms and conditions of the Creative Commons Attribution license (http://creativecommons.org/licenses/by/4.0/). 